
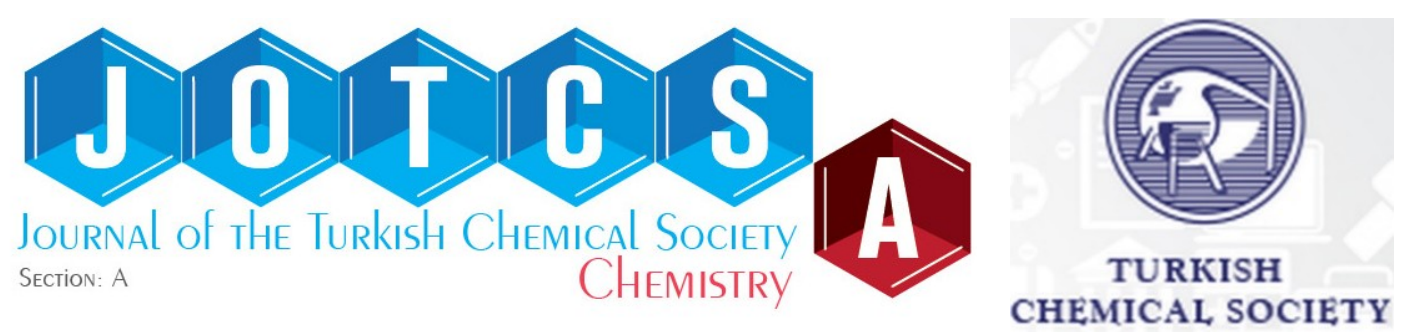

\title{
Progress and expansions of chitosan-graphene oxide hybrid networks utilizing as adsorbents and their organic dye removal performances: A short review
}

\author{
Thi Sinh Vo* $\triangle$ iD \\ School of Mechanical Engineering, Sungkyunkwan University, Suwon 16419, Korea.
}

\begin{abstract}
Increasing concentration of pollutants has significantly affected the quality of water, especially for organic dyes-contained water/wastewater. This is probably reduced effectively through adsorbing the pollutants onto potential materials-based adsorbents. Chitosan/graphene oxide (CTS/GO) hybrid networks utilizing as adsorbents are attracting considerable interest owing to the available functional groups, which can remove plenty of the organic dyes from water/wastewater. In this review, the progress and expansions of CTS/GO hybrid networks-based adsorbents are summarized and discussed in detail. Following the general introduction and properties of each material system (i.e., CTS, GO and CTS/GO hybrid networks), the CTS/GO hybrid networks-based emerging adsorbents with coupling numerous other support materials (i.e., reduced GO, magnetic iron oxide, polymeric materials, metal-organic frameworks, etc.) are compared and discussed in short, at same time that some common organic dyes used in adsorption studies are also introduced. Besides, adsorption technique and mechanisms (i.e., adsorption kinetics and isotherms) focus on the CTS/GO hybrid networks' role are discussed as well. Although there are still some challenges from the reviewed researches, the CTS/GO hybrid networks-based emerging materials can be considered promising and potential adsorbents. Moreover, this review can provide a clear overview of CTS/GO hybrid networks-based adsorbents in organic dye removal applications to readers.
\end{abstract}

Keywords: Chitosan, graphene oxide, adsorbent, organic dyes, adsorption.

Submitted: May 27, 2021. Accepted: September 23, 2021.

Cite this: Vo TS. Progress and expansions of chitosan-graphene oxide hybrid networks utilizing as adsorbents and their organic dye removal performances: A short review. JOTCSA. 2021;8(4):112136.

DOI: https://doi.org/10.18596/jotcsa.943623.

* Corresponding author. E-mail: vtsinh92@skku.edu.

\section{INTRODUCTION}

So far, organic dyes have been employed plenty in the dyeing, textiles, leather, paper, plastics, and food industries, etc.; thus, these colored matters significantly affect currently environmental problems. Various organic dye types (i.e., reactive, anionic, and cationic dyes, etc.) employed in these industries are toxic and disadvantage to the water source (1-6) (Table 1). Specifically, anionic dyes contain negative charges instead of cationic dyes with positive charges in an aqueous solution that is due to the presence of carboxyl and/or sulfonate groups (2, 5 , 6). Among them, the anionic dyes are intensely colored, water-soluble, and manifest acidic features inducing to the most challenging $(7,8)$.

Additionally, the organic molecular structures of these complex aromatic dyes display more stability inducing to being difficult to biodegrade, which leads to removing the organic dyes from water/wastewater with an economical way is 
considered to be an important challenge for scientists. In fact, primary methods regarding dye-contaminated water/wastewater treatment (i.e., flotation and sedimentation) cannot be adequate to remove the colored features without general chemical manners. The treatment methods of coagulation, separation, and ion exchange are utilized for removing the color from the dye-contaminated water/wastewater as well; however, the cost is one of the main disadvantages of these methods. Whereas, adsorption is a well-known and effective technique in dye-contaminated water/wastewater treatment applications to remove the color from the dye-containing wastewater $(4,8,9)$ that is mainly owing to low cost, flexibility, simple design, and easy operation (4).

So far, material system was extensively applied in different research fields and practical applications (4, 6, 10-12), at same time that remarkable factors of a material-based adsorbent almost regard to possible physical, chemical and interface properties. So, it is necessary to conduct considerably synthetic methods that can obtain better desired results corresponding to multiple researches. Concomitantly, the emerging materials-based adsorbents are found and utilized increasingly more to investigate the color removal from dye-contaminated water/wastewater (13-17), which can be novel, readily available, economical and highly effective adsorbents. Especially, chitosan (CTS) - a biopolymer is attracting interest as a matrix for the development of emerging material-based adsorbent that can be mainly owing to potentially active adsorption sites in a high density of available primary amine $\left(-\mathrm{NH}_{2}\right)$ and hydroxyl ($\mathrm{OH}$ ) groups; thus, the CTS is considered an efficient adsorbent $(4,6,18)$. Actually, the CTS molecule is not available that is produced through $\mathrm{N}$-deacetylation of chitin (19-22) basing on the replacement of acetamide group at position 2 to distinguish the structure and solubility of CTS and chitin molecules (Figure 1) (i.e., CTS is soluble in weak acids, chitin is inert and insoluble) (19-22). At the same time, graphene oxide (GO) contains plenty of functional surface groups [i.e., carbonyl $(>\mathrm{C}=\mathrm{O})$, epoxide $(\mathrm{C}-\mathrm{O}-\mathrm{C})$, hydroxyl $(-\mathrm{OH})$ and carboxylic $(-\mathrm{COOH})$ groups] (Figure $2 \mathrm{a})$ that can facilitate to couple with positively charged molecules through electrostatic interactions, and which attracts significantly in combing with polymer matrices for enhancement of organic dye removal, mainly based on its high surface area and water solubility $(4,6,23)$. Indeed, plenty of studies have shown the GO's excellent ability to adsorb various organic dyes through electrostatic interaction, $\pi$-stacking and hydrogen bonding (24-28). However, the organic dye adsorption performance of GO alone is lower than that of modified GO-based adsorbents $(24,25,28)$.

Furthermore, the stability of GO nanosheets in colloidal solutions can lead to coupling easily with the CTS molecules (i.e., the CTS is often dissolved in acetic acid) to reach CTS/GO hybrid networks with a homogeneous mixture (Figure $2 \mathrm{~b})$. The CTS is known as a positively charged biopolymer that is mainly owing to protonation of the amino $\left(-\mathrm{NH}_{2}\right)$ groups leading to attracting the negatively charged GO nanosheets (Figure $2 b$ ). These electrostatic interactions coupling with both hydrogen bonding and $\pi$-stacking have facilitated the formation of the CTS/GO hybrid networks (Figure $2 \mathrm{~b}$ ) to reach the more stable hybrid networks-based materials with outstandingly mechanical and thermal features $(6,29)$. Indeed, the measurement of Fouriertransform infrared spectroscopy (FTIR) (30) has been successfully employed to demonstrate the possible reaction between the amino $\left(-\mathrm{NH}_{2}\right)$ groups of the CTS chains and the carboxylic ($\mathrm{COOH}$ ) groups of $\mathrm{GO}$ basing on the formation of amide (-NHCO-) linkages (Figure 2b). So far, the CTS/GO hybrid networks can be easily attained through various methods (i.e., the supplement of $\mathrm{NaOH}$, violent shaking, sonication, freeze-drying, etc.) $(6,31-33)$, and which can also be well combined with other support material sources to develop and expand these CTS/GO hybrid networks that are applied in organic dye removal applications, especially for becoming costeffective, eco-friendly and recyclable adsorbents. In this review article, the adsorption technique regarding the general adsorption theory and the adsorption kinetics/isotherms are introduced in detail. Significantly, the recent progress and expansions of emerging CTS/GO hybrid networks-based adsorbents for various organic dye removal applications are summarized and compared to favor the reader with a clear overview. 
Vo TS. JOTCSA. 2021; 8(4): 1121-1136.

Table 1: Information of some organic dyes.

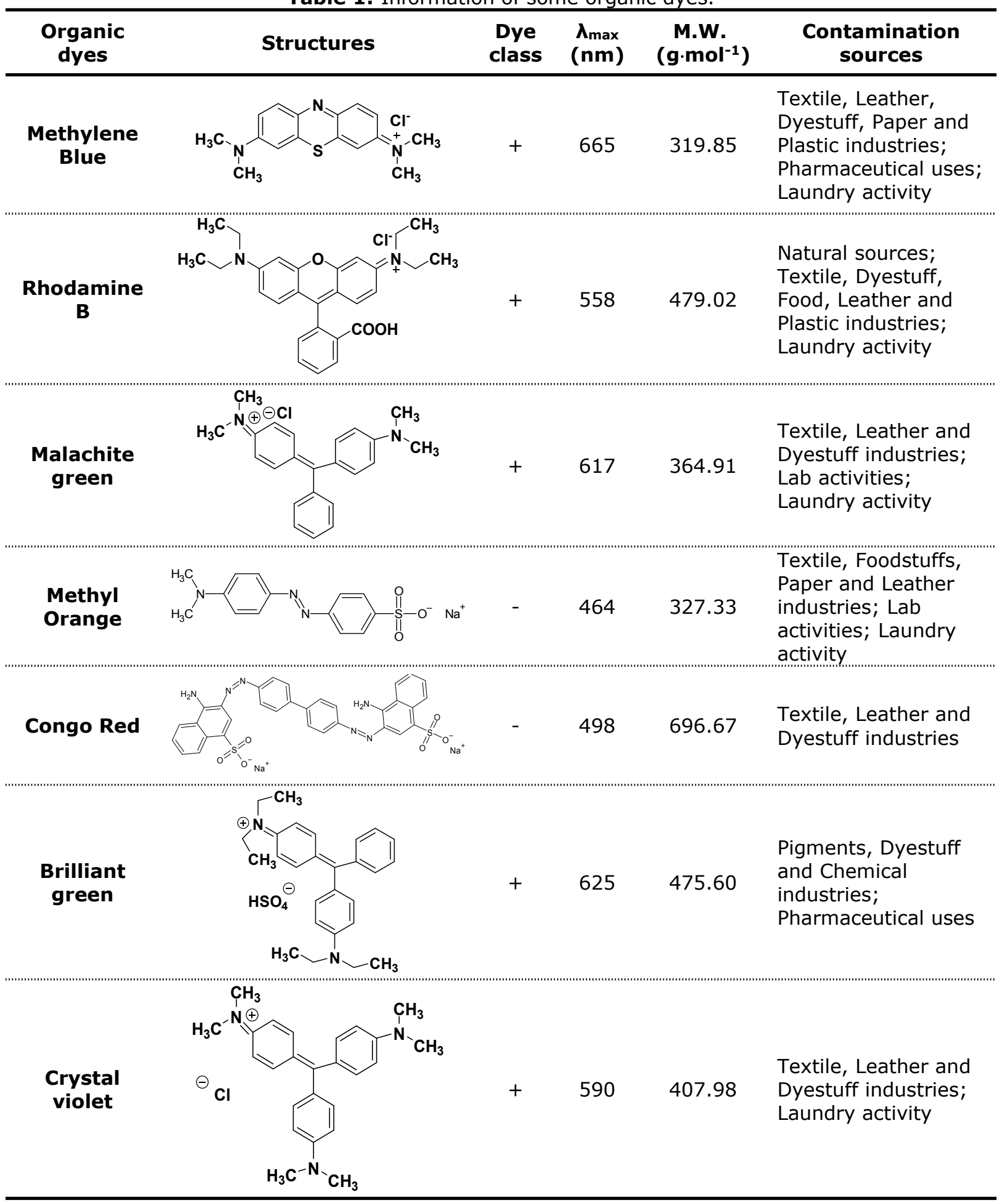




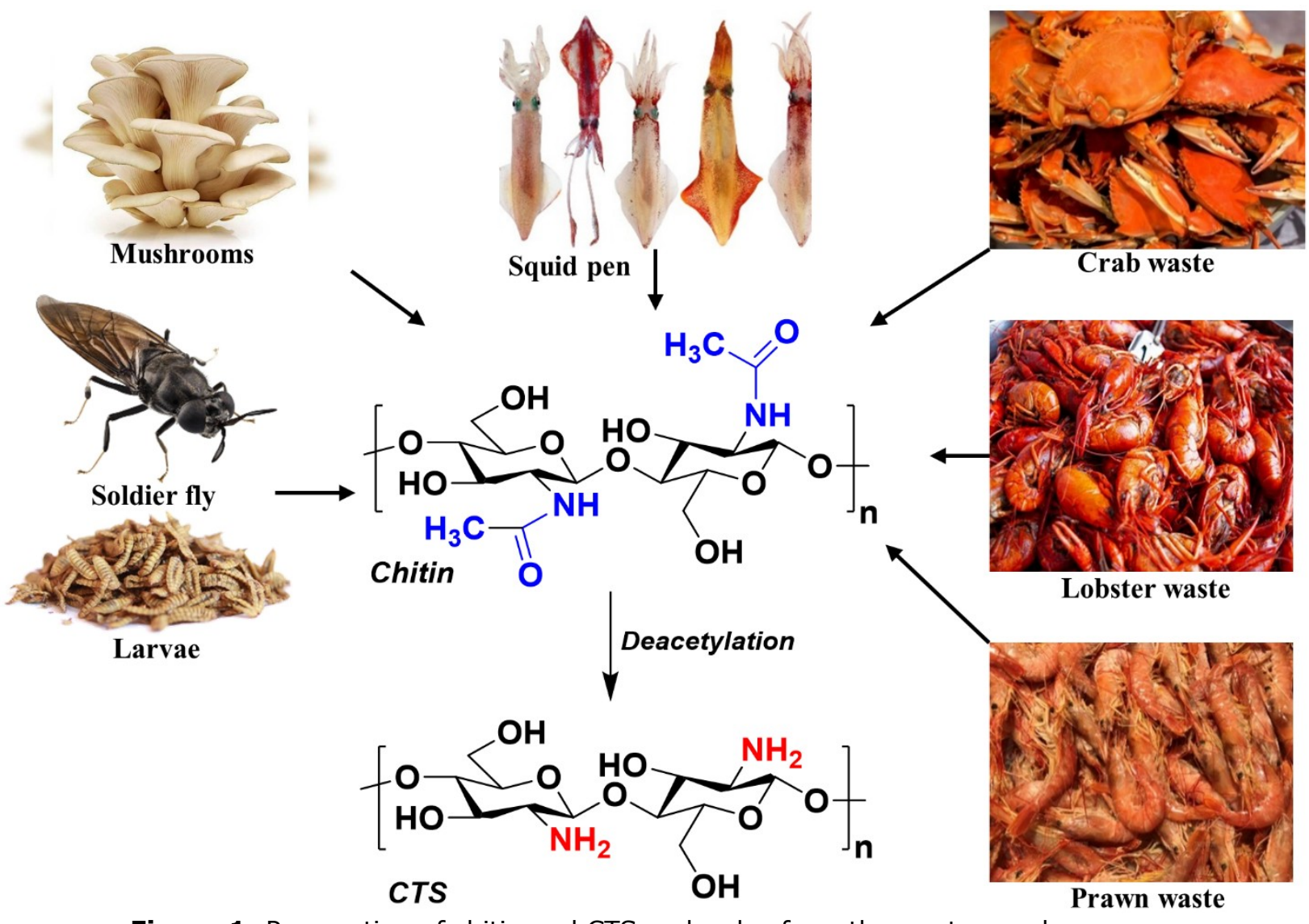

Figure 1: Preparation of chitin and CTS molecules from the waste supply sources.

\section{ADSORPTION TECHNIQUE}

Adsorption is known as a surface phenomenon, which is occurred at the surface or interface positions. In another word, it mentions a procedure in which a material is gathered at a solid surface by its gaseous or liquid surroundings. In 1881, the term "adsorption" was firstly introduced by Heinrich Kayser - a German physicist (1853-1940) in order to distinguish surface accumulation from intermolecular penetration, as well as which assumes surface accumulation of a material to be a fundamental feature of an adsorption process (4). Theoretically, two adsorption types count physisorption and chemisorption. If the attractive forces between the adsorbed molecules and the solid surface relate to van der Waals forces, which are usually weak forces inducing reversible adsorption to be named physisorption. In comparison, chemisorption involves chemical bonds between the adsorbed molecules and the solid surface, which is higher strength, leading to hard removal of the chemisorbed molecules from the solid surface (4).
Besides, adsorption techniques are extensively employed to remove plenty of pollutants from water/wastewater, especially for organic dyes that are not readily biodegradable. The general mechanism of dye adsorption consists of three steps during the process of color removal following as (34): (i) diffusion of organic dye molecules - adsorbates presented availably in the bulk solution can be onto the material-based adsorbent surface; (ii) the organic dye adsorption on the material-based adsorbent surface can base on molecular interactions (i.e., "film diffusion"); and (iii) diffusion of organic dye molecules can be moved from the surface to the inside of the materials-based adsorbents (i.e., "surface diffusion" or "pore diffusion"). The processes of diffusion and surface reaction occurring on the materials-based adsorbents are described in Figure 3. Overall, agitation and concentration of the organic dye molecules in the solution probably impact to the first step. The nature of the organic dye molecules directly influences to the second step, for example, cationic and anionic features. At the same time, the third step regards to the rate-confirming stage in this process that surely impacts to the adsorption of organic dye molecules on the 
substrates. In particular, external diffusion occurring in the adsorption processes is the most efficacy, while intraparticle diffusion will attain a longer contact time in non-flow systems. Moreover, these are influenced by physicochemical factors, examples for interactions of organic dyes and adsorbents, particle sizes, surface areas of adsorbents, $\mathrm{pH}$ values, temperatures, and contact times.

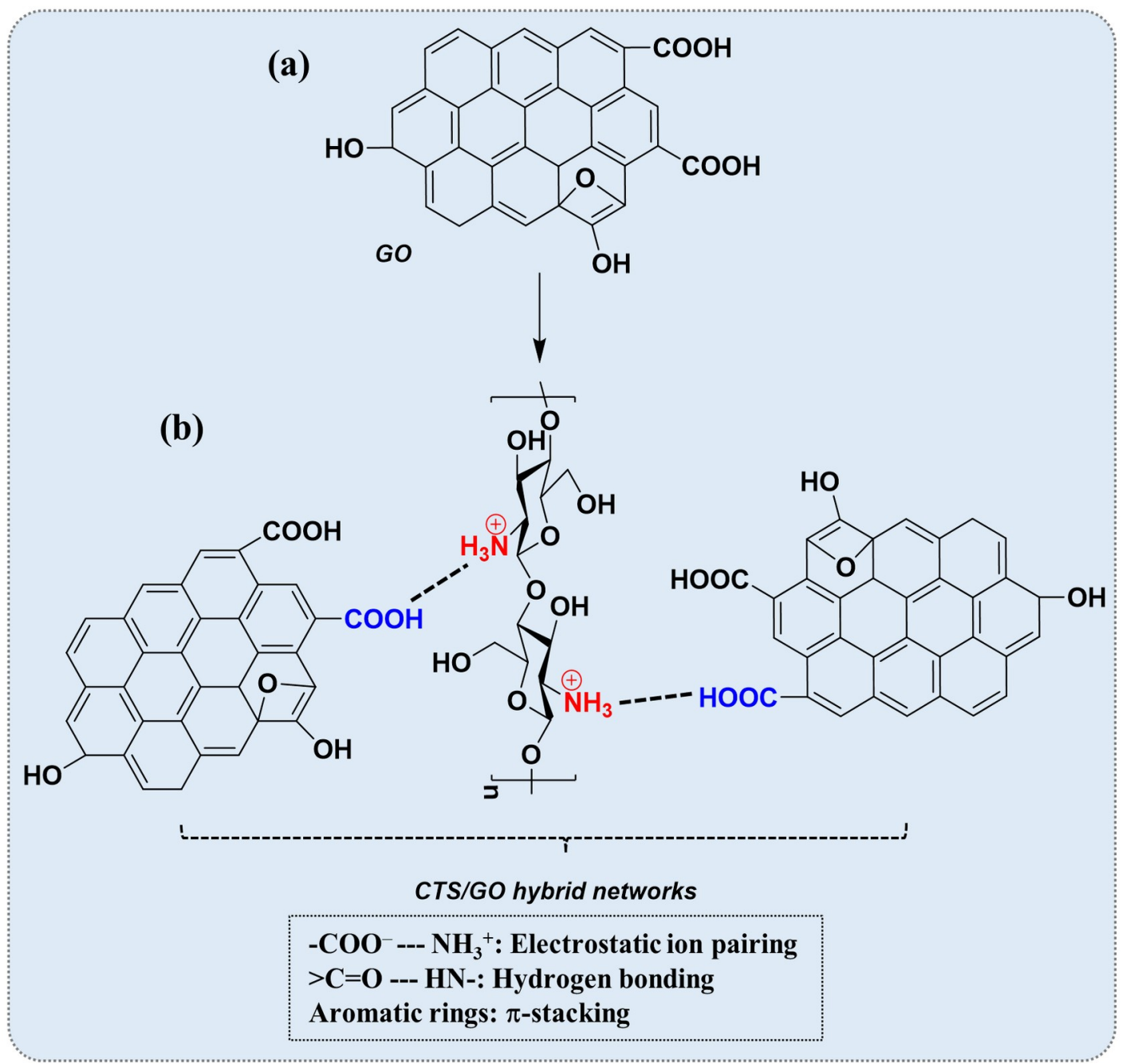

Figure 2: Schematic of chemical structure of GO (a) and possible interactions in CTS/GO hybrid networks (b). 


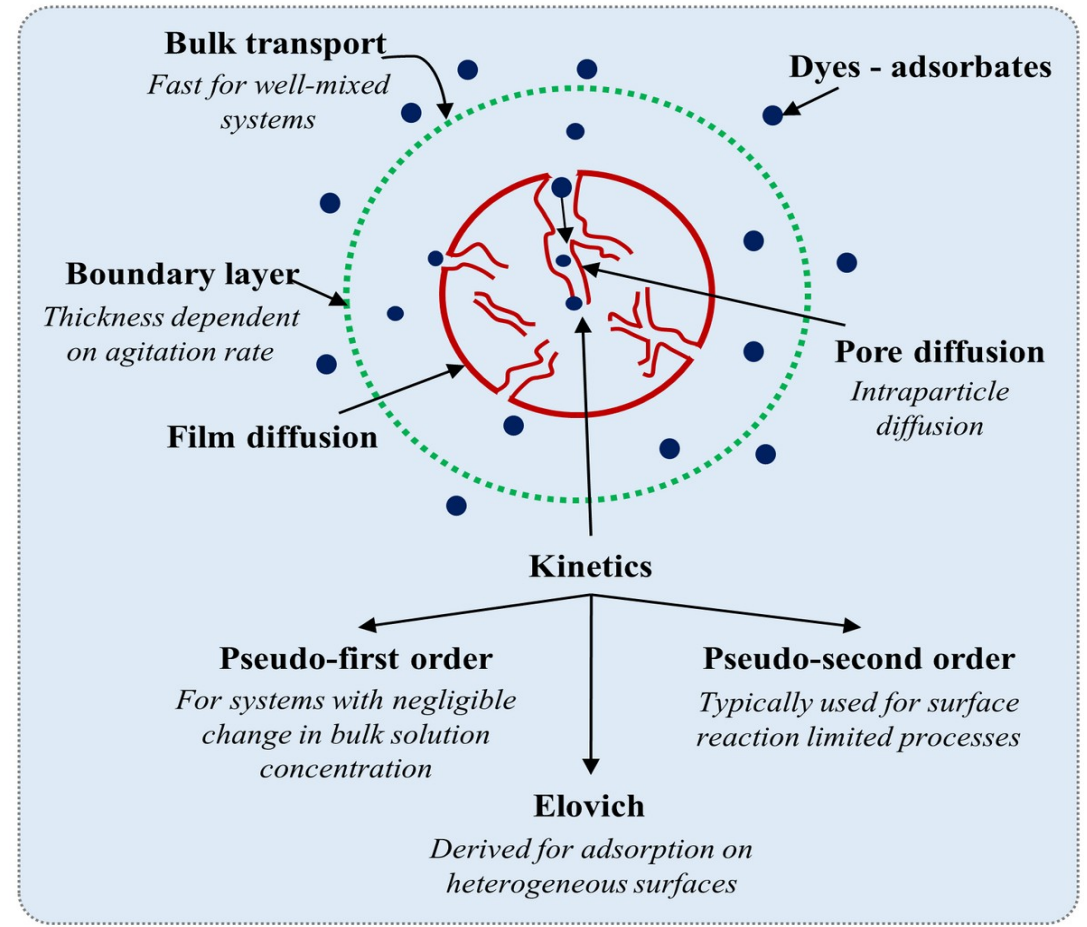

Figure 3: The processes of diffusion and surface reaction occurring on the materials-based adsorbents.

In addition, adsorption isotherms and kinetics are suitable models to evaluate the adsorption process (35). Specifically, adsorption isotherms can reach through a change in the initial concentrations of organic dye solutions, and the other corresponding parameters are constants (i.e., contact times, temperatures, $\mathrm{pH}$ values, and stirring speeds). Basically, the removal efficiency will attain high values through increases of the organic dye concentrations until no further uptake, which is named saturation or equilibrium state. The common adsorption isotherm models are listed in Table 2, which are on basic of the original and linearized forms. Concomitantly, many other models can also be employed to elucidate the mechanism of organic dye adsorption on a material-based adsorbent, e.g., common adsorption kinetic models (Table 2 and Figure 3). In fact, the adsorption kinetics are usually defined by establishing plots of the adsorbed quantity vs. a time function to manifest the possible nature of the adsorption process and the kinetics. Overall, in order to more easily understand, this review has been summarized on basic of various adsorbent types studied from the progress and expansions of CTS/GO hybrid networks-based adsorbents coupled with numerous other support materials (i.e., reduced GO, magnetic iron oxide, polymeric materials, metal-organic frameworks, etc.), as well as organic dye removal efficiency and adsorption mechanisms onto these emerging adsorbents. 
Table 2: Common adsorption isotherm and kinetic models.

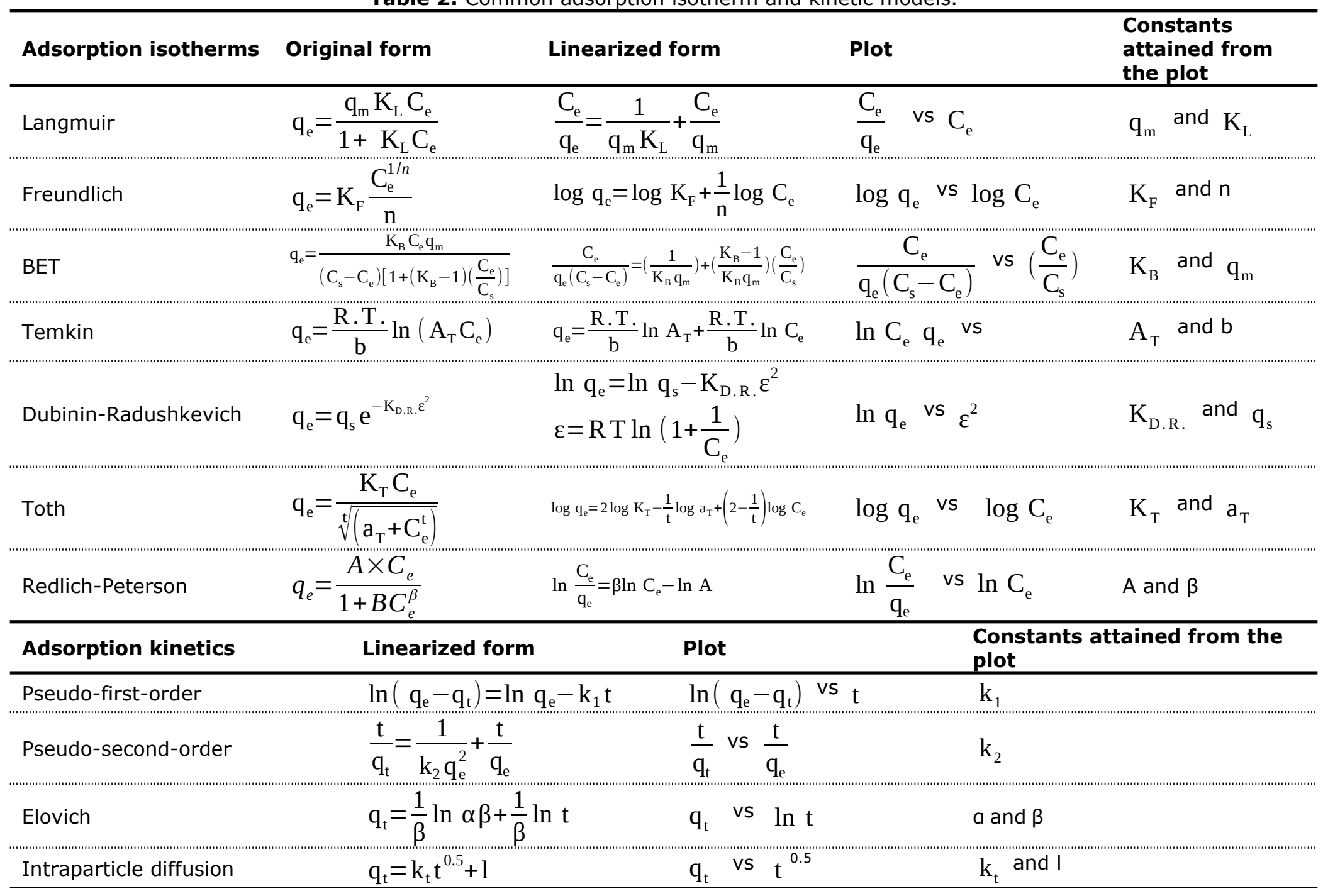


VARIOUS CTS/GO HYBRID NETWORKS-BASED ADSORBENTS AND ORGANIC DYE ADSORPTION PERFORMANCES

As known, CTS is often dissolved in acetic acid, and GO is well stable in colloidal solutions, which can easily couple together to attain CTS/GO hybrid networks with a homogeneous mixture through electrostatic interactions, hydrogen bonding, and $\pi$-stacking resulting in outstandingly mechanical and thermal features $(6,29)$. Concomitantly, the CTS/GO hybrid networks-based materials can be prepared from various methods such as supplement of $\mathrm{NaOH}$, violent shaking, sonication, freeze-drying, etc. $(6,31-33)$. As a result, the CTS/GO hybrid networks-based materials have been formed with various shapes such as membranes, beads, sponges, and columns (6, 3639), and which are all utilized successfully as effective adsorbents for organic dye removal from water/wastewater (40).

Notably, other components - support materials have been supplemented to enhance the organic dye adsorption performance of the CTS/GO hybrid networks-based materials in recent years; in particular, two-dimensional GO has also been developed to reduced GO (rGO) or threedimensional GO-based aerogels. Typically, the GO is formed through oxidizing graphite (i.e., Hummers method) (41), while the rGO is synthesized by reducing the GO (i.e., various thermal methods, reducing agents, electrochemical reduction) (42-45). Actually, the oxygencontaining functional groups on the GO are difficult to reduce, which still contained some on the rGO. Besides, the rGO can combine with various metals or metal oxide particles (46), facilitating their incorporation within the CTS molecule. For instance, CTS/rGO hybrid network has been coupled with iron oxide $\left(\mathrm{Fe}_{3} \mathrm{O}_{4}\right)$ to attain magnetic CTS/rGO hybrid network-based adsorbents that are effectively applied for the cefixime adsorption (47) (Table 3). Concomitantly, a comparison of dye removal performance of CTS/GO and CTS/rGO hybrid networks utilizing as adsorbents indicated that the CTS/GO hybrid network has adsorbed efficiently more (48) (Table 3), which can involve to the presence of more numerous available functional groups offering a combination of electrostatic interactions, hydrogen bonding and $\pi-$ stacking with the organic dye molecules $(4,6,28)$. As a result, the pseudo-second-order model studied in this research was the best model, indicated that the organic dye adsorption could be induced on the chemical rate-limiting step (i.e., electron share or covalent forces).

So far, magnetic CTS-based adsorbent has emerged as a potential material for removing pollutants from water/wastewater. There has recently been a considerable interest in the magnetic CTS/GO hybrid network-based material as well $(49,50)$ (Table 3$)$; notably, these magnetic materials have shown a fast removal performance. Obviously, the magnetism approach can facilitate well for separating the adsorbents from water/wastewater based on a simple magnetic procedure (51). In fact, separation of CTS/GO hybrid network-based materials using conventional sedimentation and filtration techniques is an important challenge due to blocked and lost filters inducing secondary contaminations. Hence, the choice of $\mathrm{Fe}_{3} \mathrm{O}_{4}$ is the most efficacy, owing to its low toxicity, good compatibility and high magnetic features (52). For preparation methods of the magnetic CTS/GO hybrid network-based materials, it can be easily created via in- or ex-situ approach, or a combination of both these approaches (49, $53)$, or alterations of these two methods $(50,54)$ (i.e., CTS/ $\mathrm{Fe}_{3} \mathrm{O}_{4}$ hybrid network can be first created before being coupled with GO, or opposite). Nonetheless, the shape and size of the $\mathrm{Fe}_{3} \mathrm{O}_{4}$ nanoparticles are also important characteristics to couple with the CTS/GO hybrid network-based materials for organic dye removal performances. Although the $\mathrm{Fe}_{3} \mathrm{O}_{4}$ nanoparticles can be easily clustered that is mainly due to their magnetic nature, several studies have also be conducted to control the suitable shape and size with the research aims (54-56). For example, $\mathrm{Fe}_{3} \mathrm{O}_{4}$ particles could be attained with the spherical shapes and $\sim 45 \mathrm{~nm}$ of size by Shafaati et al. (55), but their particle size has increased with incorporating the CTS, suggesting that the CTS chains could probably induce linking together for the neighboring $\mathrm{Fe}_{3} \mathrm{O}_{4}$ particles. Silica is employed to coat the $\mathrm{Fe}_{3} \mathrm{O}_{4}$ particles resulting from the significantly reduced agglomeration (56). Thereby, the use of silica is a promising approach to coat and protect magnetic iron-containing particles in the CTS/GO hybrid networks, as well as stability of these materials need to be investigated more to not leach the GO flakes or the magnetic iron oxide particles.

In addition, the CTS/GO (or CTS/rGO) hybrid networks-based materials with three-dimensional porous structures acting as scaffolds (i.e., aerogel, foam, sponge, column) can be fabricated through the available wrinkling and blending of GO nanosheets. These scaffolds are effectively applied in the organic dye removal applications owing to high surface areas, low mass densities (porous structure) and good mechanical strength $(57,58)$; besides, these scaffolds-based adsorbents are also easily regained from the aqueous solution after completing the adsorption procedure. Indeed, the GO or rGO alone with three-dimensional structures reach relatively poor stability in water, but this stability can be improved significantly through a combination of the three-dimensional GO or rGO network and the CTS molecules. For instance, the three-dimensional CTS/GO hybrid network-based columns have been successfully applied in five adsorption-regeneration cycles reaching $>90 \%-$ adsorption performances $(6,32)$, and the layered CTS/GO hybrid network-based sponges have also been attained good stability and effective recyclability resulting in $>80 \%$-adsorption performances over five adsorption-regeneration cycles (59). Besides, plenty of studies on CTS/GO 
hybrid network-based aerogel have been successfully fabricated to remove effectively azo dyes, anionic and cationic dyes $(60,61)$ from water.

Furthermore, other additives - support materials have been coupled with the CTS/GO hybrid network to become potential and outstanding materials-based adsorbents in environmental applications. For example, $\beta$-cyclodextrin (Figure 4) has been combined with the CTS/GO hybrid network to enhance the adsorption performance of methylene blue following GO $<$ CTS/GO < CTS/GO/ $\beta$-cyclodextrin networks (62), similarly for a study on the adsorption performance of hydroquinone and dye molecules (63) (Table 3). Besides, polypyrrole (Figure 4) has also been used to couple with the CTS/GO hybrid network basing on polymerization of the pyrrole monomer in the above-mentioned hybrid network, resulting in the ternary CTS/GO/polypyrrole hybrid network-based material that could become efficient adsorbents in the organic dye removal applications $(64,65)$ (Table 3). Interestedly, these hybrid networksbased adsorbents could incorporate magnetic nanoparticles to improve the separation of these adsorbents from water/wastewater after completing the organic dye adsorption process (66) (Table 3). Concomitantly, other polymers with high molecular weights (i.e., polydopamine, polyacrylamide, and polyacrylate are shown in Figure 4) have also been employed to combine with the CTS/GO hybrid network (67-69) that could significantly enhance the swelling and adsorption performances of these hybrid networksbased adsorbents (Table 3). In another word, these support materials have offered different binding sites to enhance the adsorption performances, and which are considered promising materials-based adsorbents.

More notably, metal-organic frameworks (MOFs) have recently attracted much interest in environmental applications that is mainly due to their high surface areas and porosities and controlled pore structures. Thus, they have been used to add into the CTS/GO hybrid network that enhances adsorption performance (70, 71). Unfortunately, the MOFs are powdered materials that are hard to separate from water, which is its main limitation in environmental applications. Thereby, the CTS/GO hybrid network can be contributed like a matrix to encapsulate these powdered materials that can couple with magnetic iron to result in a necessary magnetic separation. Besides, plenty of other support materials has also been combined with the CTS/GO hybrid network; for examples, the use of hydroxyapatite $\left[\mathrm{Ca}_{10}\left(\mathrm{PO}_{4}\right)_{6}(\mathrm{OH})_{2}\right]$ has increased strength and organic pollutant adsorption performance (72), the use of silica (numerous silanol groups, $\mathrm{Si}-\mathrm{OH}$ ) has favored a good dispersion of GO nanosheets within CTS to reach effective adsorbents $(73,74)$, the use of triethylenetetramine and lignosulfonate (Figure 4) have supplied amine groups and different binding sites to enhance adsorption performance, respectively (75-77) (Table 3 ). In general, these studies manifested that these materials could become cost-effective, eco-friendly, and recyclable adsorbents for organic dye removal applications. Additionally, other biopolymers (i.e., gelatin, alginate, heparin, and cellulose are shown in Figure 4) have been blended with the CTS to create polymeric mixtures, which are then coupled with the GO nanosheets to attain outstanding performing adsorbents (78-81). Overall, the pseudo-second-order model studied in these researches were the best model; nonetheless, the kinetic studies need to investigate more, and the chemical/physical characterizations of the CTS can be focused more on the degree of deacetylation levels, molecular weight, etc., similarly, for the GO. Also, it is needed to develop further suitable recovery systems, as well as preparation process of the adsorbents should be employed green solvents and material sources. 


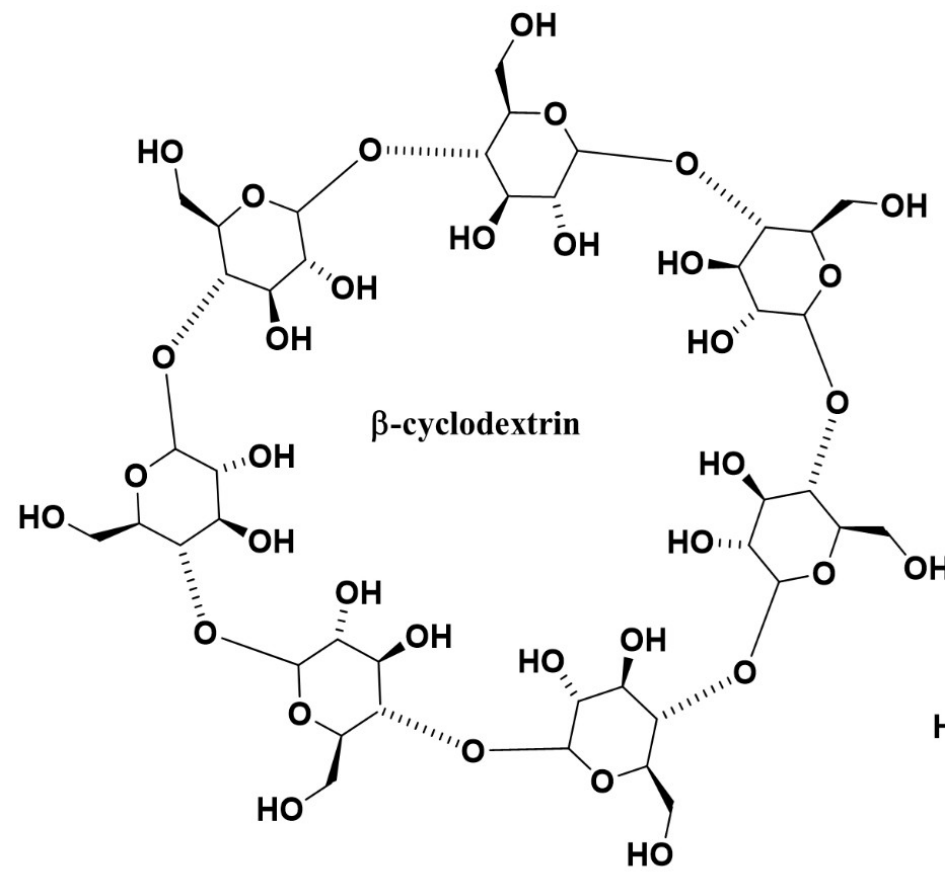<smiles>CC(N)C(CCC(N)C(C(=O)O)C(N)C(N)CCC(N)C(C(=O)O)C(C(=O)O)C(=O)O)C(=O)O</smiles>

Gelatin<smiles>NCCNCCNCCN</smiles>

Triethylenetetramine

Cellulose<smiles>CC(C)(C)OC(=O)C1C(O)C(O)C(C(C)(C)C)C(O)C1C(=O)[O-]</smiles>

Alginate<smiles>CC(C)(C)CC(C(N)=O)C(C)(C)C</smiles>

Polyacrylamide<smiles>[R]OC(=O)C(CC(C)(C)C)C(C)(C)C</smiles>

Polyacrylate

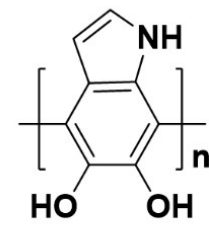

Polydopamine

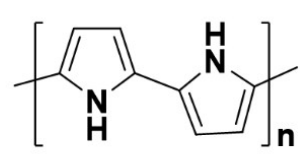

Polypyrrole

Figure 4: Chemical structures of various additives.

Table 3. Adsorption data of various CTS/GO hybrid networks-based adsorbents.

\begin{tabular}{|c|c|c|c|c|}
\hline Adsorbents & Organic dyes & $\begin{array}{l}\text { Adsorption } \\
\text { performance } \\
\left(\% \text {, or } \mathbf{~ m g} \cdot \mathrm{g}^{-1}\right)\end{array}$ & $\begin{array}{l}\text { Adsorption } \\
\text { isotherm } \\
\text { models }\end{array}$ & $\begin{array}{l}\text { Adsorption kinetic } \\
\text { models }\end{array}$ \\
\hline CTS/GO_1/15 (6) & $\begin{array}{l}\text { Methylene blue, } \\
\text { Rhodamine B, } \\
\text { Congo Red, } \\
\text { Methyl orange }\end{array}$ & $\begin{array}{l}\sim 95.0 \% \\
>90.0 \% \\
\sim 70.0 \% \\
\sim 80.0 \%\end{array}$ & -- & -- \\
\hline CTS/GO (48) & Reactive Red & $32.2 \mathrm{mg} \cdot \mathrm{g}^{-1}$ & Langmuir & Pseudo-second order \\
\hline Magnetic CTS/rGO & Cefixime & $30.6 \mathrm{mg} \cdot \mathrm{g}^{-1}$ & Freundlich & -- \\
\hline $\begin{array}{l}\text { Magnetic CTS/GO } \\
(49)\end{array}$ & Methylene blue & $74.93 \mathrm{mg} \cdot \mathrm{g}^{-1}$ & Freundlich & Pseudo-second order \\
\hline $\begin{array}{l}\text { CTS/GO/ } \beta- \\
\text { cyclodextrin (62) }\end{array}$ & Methylene blue & $1134.0 \mathrm{mg} \cdot \mathrm{g}^{-1}$ & Freundlich & Pseudo-second order \\
\hline $\begin{array}{l}\text { Magnetic } \\
\text { CTS/GO/ } \beta- \\
\text { cyclodextrin (63) }\end{array}$ & Methylene blue & $84.3 \mathrm{mg} \cdot \mathrm{g}^{-1}$ & Langmuir & Pseudo-second order \\
\hline
\end{tabular}




\begin{tabular}{|c|c|c|c|c|}
\hline $\begin{array}{l}\text { Polypyrrole/CTS/GO } \\
(64)\end{array}$ & Ponceau 4R & $5.4 \mathrm{mg} \cdot \mathrm{g}^{-1}$ & Langmuir & Pseudo-second order \\
\hline \multicolumn{5}{|l|}{ Magnetic } \\
\hline Polypyrrole/CTS/GO & Ponceau 4R & $5.1 \mathrm{mg} \cdot \mathrm{g}^{-1}$ & Langmuir & Pseudo-second order \\
\hline \multicolumn{5}{|l|}{ CTS/ } \\
\hline Polyacrylamide/GO & Methylene blue & $510.2 \mathrm{mg} \cdot \mathrm{g}^{-1}$ & Langmuir & Pseudo-second order \\
\hline $\begin{array}{l}\text { CTS/polyacrylate/ } \\
\text { GO (68) }\end{array}$ & $\begin{array}{l}\text { Methylene blue, } \\
\text { Food yellow } 3\end{array}$ & $\begin{array}{l}296.5 \mathrm{mg} \cdot \mathrm{g}^{-1}, \\
280.3 \mathrm{mg} \cdot \mathrm{g}^{-1}\end{array}$ & -- & $\begin{array}{l}\text { Pseudo-first order, } \\
\text { Pseudo-second order }\end{array}$ \\
\hline $\begin{array}{l}\text { CTS/GO/ } \\
\text { Hydroxyapatite (72) }\end{array}$ & $\begin{array}{l}\text { Congo Red, } \\
\text { Acid Red 1, } \\
\text { Reactive Red } 2\end{array}$ & $\begin{array}{l}43.1 \mathrm{mg} \cdot \mathrm{g}^{-1} \\
41.3 \mathrm{mg} \cdot \mathrm{g}^{-1} \\
40.0 \mathrm{mg} \cdot \mathrm{g}^{-1}\end{array}$ & Freundlich & Pseudo-second order \\
\hline $\begin{array}{l}\text { CTS/ } \\
\text { lignosulfonate/GO } \\
\text { (75) }\end{array}$ & Methylene blue & $1023.9 \mathrm{mg} \cdot \mathrm{g}^{-1}$ & Langmuir & Pseudo-second order \\
\hline $\begin{array}{l}\text { Magnetic } \\
\text { CTS/lignosulfonate/ } \\
\text { GO (76) }\end{array}$ & Methylene blue & $253.5 \mathrm{mg} \cdot \mathrm{g}^{-1}$ & Langmuir & Pseudo-second order \\
\hline
\end{tabular}

\section{CONCLUSIONS AND FUTURE RESEARCH OUTLOOKS}

With a large number of publications, the CTS/GO hybrid networks-based materials are employed as potential and interesting adsorbents for various organic dye removal applications. In summary, the CTS/GO hybrid networks easily couple with numerous other components or additives - support materials (i.e., rGO, magnetic iron oxide, polymeric materials, MOFs, etc.) that is attracting considerable attention, as well as the CTS/GO hybrid networks-based materials have attained not only magnificent adsorption capacity with organic dyes but also heavy metal ions. Nonetheless, several challenges still exist for removing a variety of pollutants directly implicating in terms of costs, which regards the regeneration of the CTS/GO hybrid networks-based adsorbents. These adsorbents should be effectively regenerated to can be employed multiple times in the adsorption process, which relates to washing-solvents and natures of polysaccharide/carbon-based materials (CTS/GO); thus, the adsorption capacity can reduce with each cycle of adsorption-regeneration (i.e., the polysaccharide hydrolysis on the CTS). These require an offer of more longer-lasting and cost-effective CTS/GO hybrid networks-based adsorbents.

In addition to the effective performances of these adsorbents, they also need to be removed from the aqueous solution after completing the adsorption purposes, especially for the magnetic CTS/GO hybrid networks. Concomitantly, there are also concerns about the environmental influences of other CTS/GO hybrid networks-based adsorbents, which can adversely impact to the water environment if these materials-based adsorbents are leached. Consequently, the emerging CTS/GO hybrid networks-based adsorbents have to be stable and not leach regarding other support materials (i.e., magnetic iron oxide particles, GO flakes, and MOFs, etc.), which is considered as one of the importantly environmental perspectives. The other studies on intraparticle diffusion and adsorption kinetics also need to be investigated further, although most studied kinetic models regarded to pseudo-secondorder models. These emerging materials-based adsorbents are attractive and potential materials that is probably due to the abundance supply source from chitin (seafood waste sources), and expansion of these materials in the various preparation methods and high-performance studies. Besides, the recent development has attended to new two-dimensional materials (i.e., $\mathrm{MoS}_{2}, \mathrm{MXenes}$, and $\mathrm{MoSe}_{2}$ ), which are potential support materials utilized as emerging adsorbents and can easily couple with the CTS or CTS/GO hybrid networks to generate novel materials-based adsorbents with outstanding performances.

\section{REFERENCES}

1. Ceylan H, Pekdemir AD, Önal M, Sarikaya Y. The Effect of the Hydrothermal and Thermal Deactivations on the Adsorptive Properties and Liquid Permeability of a Silica Gel. Journal of the Turkish Chemical Society Section A: Chemistry [Internet]. 2021 Mar 14; 8(2): 477-82. <DOI>.

2. İlbay Z, Yildirir E. Vermicompost as a potential adsorbent for the adsorption of methylene blue dye from aqueous soulutions. Journal of the Turkish Chemical Society Section A: Chemistry. 2020 Oct 23;893-902. <DOI>.

3. Lalikoğlu M. Mg-Al Layered Double Hydroxide (LDH) as an Adsorbent for Removal of Itaconic Acid from Aqueous Solutions: Equilibrium and Kinetic Study. Journal of the Turkish Chemical Society Section A: Chemistry. 2020 Dec 5;103-16. $\leq$ DOI $>$.

4. Vo TS, Hossain MM, Jeong HM, Kim K. Heavy metal removal applications using adsorptive membranes. Nano Convergence. 2020 Dec;7(1):36. <DOI>. 
5. Yildirim A, Acay $H$, Baran A. Synthesis and characterization of molecularly imprinted composite as a novel adsorbent and competition with non-imprinting composite for removal of dye. Journal of the Turkish Chemical Society Section A: Chemistry. 2021 May 4;609-22. <DOI>.

6. Vo TS, Vo TTBC, Suk JW, Kim K. Recycling performance of graphene oxide-chitosan hybrid hydrogels for removal of cationic and anionic dyes. Nano Convergence. 2020 Dec;7(1):4. <DOI>.

7. Aksu Z, Tezer S. Biosorption of reactive dyes on the green alga Chlorella vulgaris. Process Biochemistry. 2005 Mar;40(3-4):1347-61. $<$ DOI $>$.

8. Salleh MAM, Mahmoud DK, Karim WAWA, Idris A. Cationic and anionic dye adsorption by agricultural solid wastes: A comprehensive review. Desalination. 2011 Oct;280(1-3):1-13. <DOI>.

9. Sanghi R, Bhattacharya B. Review on decolorisation of aqueous dye solutions by low cost adsorbents. Coloration Technol. 2002 Sep; 118(5):256-69. <DOI>.

10. Vo TS, Vo TTBC. Preparation and Characterization of Bis-Propargyl-Succinate, and its Application in Preliminary Healing Ability of Crosslinked Polyurethane using" Azide-Alkyne" Click. Journal of Engineering Science \& Technology Review. 2020;13(4): 110-6.

11. Vo TS, Vo TTBC, Tien TT, SiNh NT. Enhancement of mechanical property of modified polyurethane with bis-butyl succinate. Journal of the Turkish Chemical Society Section A: Chemistry. 2021 Mar 30;519-26. <DOI.

12. Vo TS, Vo TTBC. A Self-Healing Material Based on Microcapsules of Poly(Urea-Formaldehyde)/BisPropargyl-Succinate Containing in Polyurethane Matrix. Journal of the Turkish Chemical Society Section A: Chemistry. 2021 Jul 26;787-802. $\leq \mathrm{DOI}>$.

13. Crini G. Non-conventional low-cost adsorbents for dye removal: A review. Bioresource Technology. 2006 Jun;97(9):1061-85. <DOI>.

14. Gupta VK, Carrott PJM, Ribeiro Carrott MML, Suhas. Low-Cost Adsorbents: Growing Approach to Wastewater Treatment - a Review. Critical Reviews in Environmental Science and Technology. 2009 Oct 9;39(10):783-842. <DOI>.

15. Gurbanova M, LoboiChenko V, Leonova N, Strelets V. Effect Of Inorganic Components Of Fire Foaming Agents On The Aquatic Environment. Journal of the Turkish Chemical Society Section A: Chemistry. 2020 Oct 27;833-44. <DOI>.

16. Nworie F, Ebunoha J. Hydrothermal Synthesis of Fluorescent Schiff Base Functionalized Carbon Dot Composite for The Removal Of $\mathrm{Cd}(\mathrm{II})$ Ions
From Aqueous Solution: Equilibrium and Kinetic Studies. Journal of the Turkish Chemical Society Section A: Chemistry. 2020 Aug 2;137-56. $\leq \mathrm{DOI}>$.

17. Yakişik H, Özveren U. Synthesis of Polyaniline / Biochar composite material and modeling with nonlinear model for removal of copper(II) heavy metal ions. Journal of the Turkish Chemical Society Section A: Chemistry. 2021 Feb 28;8(1):291-304. $<$ DOI $>$.

18. Ceylan S, Alatepeli B. Evaluation of PVA/Chitosan Cryogels as Potential Tissue Engineering Scaffolds; Synthesis, cytotoxicity and genotoxicity investigations. Journal of the Turkish Chemical Society Section A: Chemistry. 2020 Nov 20;69-78. <DOI>.

19. Islam S, Bhuiyan MAR, Islam MN. Chitin and Chitosan: Structure, Properties and Applications in Biomedical Engineering. J Polym Environ. 2017 Sep;25(3):854-66. <DOI>.

20. Rinaudo M. Chitin and chitosan: Properties and applications. Progress in Polymer Science. 2006 Jul;31(7):603-32. <DOI>.

21. Dutta PK, Dutta J, Tripathi V. Chitin and chitosan: Chemistry, properties and applications. 2004; Journal of Scientific \& Industrial Research. 2004;63: 20-31.

22. Vo TS, Vo TTBC, Nguyen TS, Pham ND. Incorporation of hydroxyapatite in crosslinked gelatin/chitosan/poly(vinyl alcohol) hybrids utilizing as reinforced composite sponges, and their water absorption ability. Progress in Natural Science: Materials International. 2021 Sep;S1002007121001349. <DOI>.

23. Tamer $\mathrm{Y}$, Özeren MD, Berber $\mathrm{H}$. High Adsorption Performance of Graphene Oxide Doped Double Network Hydrogels for Removal of Azo Dyes from Water and Their Kinetics. J Polym Environ [Internet]. 2021 May 12 [cited 2021 Sep 30]; $\leq$ URL $>$.

24. Li Y, Du Q, Liu T, Sun J, Wang Y, Wu S, et al. Methylene blue adsorption on graphene oxide/calcium alginate composites. Carbohydrate Polymers. 2013 Jun;95(1):501-7. <DOI.

25. Wu Z, Zhong $H$, Yuan $X$, Wang $H$, Wang $L$, Chen $X$, et al. Adsorptive removal of methylene blue by rhamnolipid-functionalized graphene oxide from wastewater. Water Research. 2014 Dec;67:330-44. <DOI $>$.

26. Sitko R, Musielak M, Zawisza B, Talik E, Gagor A. Graphene oxide/cellulose membranes in adsorption of divalent metal ions. RSC Adv. 2016;6(99):96595-605. <DOI>.

27. Musielak M, Gagor A, Zawisza B, Talik E, Sitko R. Graphene Oxide/Carbon Nanotube Membranes 
for Highly Efficient Removal of Metal Ions from Water. ACS Appl Mater Interfaces. 2019 Aug 7;11(31):28582-90. <DOI>.

28. Ramesha GK, Vijaya Kumara A, Muralidhara $\mathrm{HB}$, Sampath S. Graphene and graphene oxide as effective adsorbents toward anionic and cationic dyes. Journal of Colloid and Interface Science. 2011 Sep;361(1):270-7. <DOI>.

29. Yang $X$, Tu Y, Li L, Shang S, Tao X. WellDispersed Chitosan/Graphene Oxide Nanocomposites. ACS Appl Mater Interfaces. 2010 Jun $23 ; 2(6): 1707-13$. <DOI $>$.

30. Fan L, Luo C, Li $X$, Lu F, Qiu $H$, Sun $M$. Fabrication of novel magnetic chitosan grafted with graphene oxide to enhance adsorption properties for methyl blue. Journal of Hazardous Materials. 2012 May;215-216:272-9. <DOI>.

31. Javadi $E$, Baghdadi $M$, Taghavi $L$, Ahmad Panahi H. Removal of 4-nonylphenol from Surface Water and Municipal Wastewater Effluent Using Three-Dimensional Graphene Oxide-Chitosan Aerogel Beads. Int J Environ Res. 2020 Oct; 14(5):513-26. <DOI>.

32. Lai KC, Lee LY, Hiew BYZ, Yang TC-K, Pan G-T, Thangalazhy-Gopakumar $S$, et al. Utilisation of eco-friendly and low cost 3D graphene-based composite for treatment of aqueous Reactive Black 5 dye: Characterisation, adsorption mechanism and recyclability studies. Journal of the Taiwan Institute of Chemical Engineers. 2020 Sep;114:57-66. <DOI>.

33. Zhang $M$, Ma G, Zhang $L$, Chen $H$, Zhu L, Wang $C$, et al. Chitosan-reduced graphene oxide composites with 3D structures as effective reverse dispersed solid phase extraction adsorbents for pesticides analysis. Analyst. 2019;144(17):516471. $\leq \mathrm{DOI}>$.

34. Khraisheh MAM, Al-Ghouti MA, Allen SJ, Ahmad $M N$. Effect of $\mathrm{OH}$ and silanol groups in the removal of dyes from aqueous solution using diatomite. Water Research. 2005 Mar;39(5):922-32. <DOI>.

35. Allen SJ, Mckay G, Porter JF. Adsorption isotherm models for basic dye adsorption by peat in single and binary component systems. Journal of Colloid and Interface Science. 2004 Dec;280(2):322-33. <DOI>.

36. Qi C, Zhao L, Lin Y, Wu D. Graphene oxide/chitosan sponge as a novel filtering material for the removal of dye from water. Journal of Colloid and Interface Science. 2018 May;517:1827. $\leq$ DOI $>$.

37. Croitoru A-M, Ficai A, Ficai D, Trusca R, Dolete G, Andronescu E, et al. Chitosan/Graphene Oxide Nanocomposite Membranes as Adsorbents with Applications in Water Purification. Materials. 2020 Apr 4;13(7):1687. <DOI>.
38. Kamal MA, Bibi S, Bokhari SW, Siddique AH, Yasin T. Synthesis and adsorptive characteristics of novel chitosan/graphene oxide nanocomposite for dye uptake. Reactive and Functional Polymers. 2017 Jan;110:21-9. <DOI>.

39. Li K, Zhao B, Yu Q, Xu J, Li X, Wei D, et al. Porous graphene oxide/chitosan beads with honeycomb-biomimetic microchannels as hydrophilic adsorbent for the selective capture of glycopeptides. Microchim Acta. 2020 Jun;187(6):324. <DOI>.

40. Aili Y. Preparation and Adsorption Properties of Composite Adsorbent Graphene Oxide-Chitosan. Rare metal materials and engineering. 2018;47(5):1583-8.

41. Eda G, Chhowalla M. Chemically Derived Graphene Oxide: Towards Large-Area Thin-Film Electronics and Optoelectronics. Adv Mater. 2010 Jun 2;22(22):2392-415. <DOI>.

42. Pei $\mathrm{S}$, Cheng $\mathrm{H}-\mathrm{M}$. The reduction of graphene oxide. Carbon. 2012 Aug;50(9):3210-28. <DOI>.

43. Zhang J, Yang $H$, Shen $G$, Cheng $P$, Zhang J, Guo S. Reduction of graphene oxide via I -ascorbic acid. Chem Commun. 2010;46(7):1112-4. $\leq \mathrm{DOI}>$.

44. Wang Z, Zhou X, Zhang J, Boey F, Zhang H. Direct Electrochemical Reduction of Single-Layer Graphene Oxide and Subsequent Functionalization with Glucose Oxidase. J Phys Chem C. 2009 Aug $13 ; 113(32): 14071-5$. <DOI>.

45. Shao Y, Wang J, Engelhard M, Wang C, Lin Y. Facile and controllable electrochemical reduction of graphene oxide and its applications. J Mater Chem. 2010;20(4):743-8. <DOI .

46. Sreeprasad TS, Maliyekkal SM, Lisha KP, Pradeep T. Reduced graphene oxide-metal/metal oxide composites: Facile synthesis and application in water purification. Journal of Hazardous Materials. 2011 Feb;186(1):921-31. <DOI>

47. Ciğeroğlu Z, Küçükyıldız G, Erim B, Alp E. Easy preparation of magnetic nanoparticles-rGOchitosan composite beads: Optimization study on cefixime removal based on RSM and ANN by using Genetic Algorithm Approach. Journal of Molecular Structure. 2021 Jan;1224:129182. <DOI>.

48. Guo X, Qu L, Tian M, Zhu S, Zhang X, Tang X, et al. Chitosan/Graphene Oxide Composite as an Effective Adsorbent for Reactive Red Dye Removal. water environ res. 2016 Jul 1;88(7):579-88. <DOI $>$.

49. Singh N, Riyajuddin S, Ghosh K, Mehta SK, Dan A. Chitosan-Graphene Oxide Hydrogels with Embedded Magnetic Iron Oxide Nanoparticles for 
Dye Removal. ACS Appl Nano Mater. 2019 Nov 22;2(11):7379-92. <DOI $>$.

50. Rebekah A, Bharath G, Naushad Mu, Viswanathan C, Ponpandian N. Magnetic graphene/chitosan nanocomposite: A promising nano-adsorbent for the removal of 2-naphthol from aqueous solution and their kinetic studies. International Journal of Biological Macromolecules. 2020 Sep;159:530-8. <DOI .

51. Kharissova OV, Dias HVR, Kharisov BI. Magnetic adsorbents based on micro- and nanostructured materials. RSC Adv. 2015;5(9):6695719. $\leq \mathrm{DOI}>$.

52. Shan $H$, Peng S, Zhao C, Zhan $H$, Zeng C. Highly efficient removal of As(III) from aqueous solutions using goethite/graphene oxide/chitosan nanocomposite. International Journal of Biological Macromolecules. 2020 Dec;164:13-26. <DOI>.

53. Xu L, Suo H, Wang J, Cheng F, Liu H, Qiu H. Magnetic graphene oxide decorated with chitosan and $\mathrm{Au}$ nanoparticles: synthesis, characterization and application for detection of trace rhodamine $B$. Anal Methods. 2019;11(30):3837-43. <DOI>.

54. Tasmia, Shah J, Jan MR. Microextraction of Selected Endocrine Disrupting Phenolic Compounds using Magnetic Chitosan Biopolymer Graphene Oxide Nanocomposite. J Polym Environ. 2020 Jun;28(6):1673-83. <DOI $>$.

55. Shafaati M, Miralinaghi M, Shirazi RHSM, Moniri E. The use of chitosan/Fe3O4 grafted graphene oxide for effective adsorption of rifampicin from water samples. Res Chem Intermed. 2020 Dec;46(12):5231-54. <DOI>.

56. Jiang $X$, Pan W, Chen $M$, Yuan $Y$, Zhao L. The fabrication of a thiol-modified chitosan magnetic graphene oxide nanocomposite and its adsorption performance towards the illegal drug clenbuterol in pork samples. Dalton Trans. 2020;49(18):6097107. $\leq \mathrm{DOI}>$.

57. Ma Y, Chen Y. Three-dimensional graphene networks: synthesis, properties and applications. National Science Review. 2015 Mar 1;2(1):40-53. $\leq$ DOI $>$.

58. Sun Z, Fang S, Hu YH. 3D Graphene Materials: From Understanding to Design and Synthesis Control. Chem Rev. 2020 Sep 23;120(18):10336453. $\leq \mathrm{DOI}>$.

59. Zhang D, Li N, Cao S, Liu X, Qiao M, Zhang P, et al. A Layered Chitosan/Graphene Oxide Sponge as Reusable Adsorbent for Removal of Heavy Metal Ions. Chem Res Chin Univ. 2019 Jun;35(3):46370. $\leq \mathrm{DOI}>$.

60. Wang Y, Xia G, Wu C, Sun J, Song R, Huang $W$. Porous chitosan doped with graphene oxide as highly effective adsorbent for methyl orange and amido black 10B. Carbohydrate Polymers. 2015 Jan;115:686-93. <DOI>.

61. Salzano de Luna M, Ascione C, Santillo C, Verdolotti L, Lavorgna M, Buonocore GG, et al. Optimization of dye adsorption capacity and mechanical strength of chitosan aerogels through crosslinking strategy and graphene oxide addition. Carbohydrate Polymers. 2019 May;211:195-203. $\leq$ DOI $>$.

62. Liu Y, Huang S, Zhao X, Zhang Y. Fabrication of three-dimensional porous $\beta$-cyclodextrin/chitosan functionalized graphene oxide hydrogel for methylene blue removal from aqueous solution. Colloids and Surfaces A: Physicochemical and Engineering Aspects. 2018 Feb;539:1-10. <DOI>.

63. Fan L, Luo C, Sun M, Qiu H, Li X. Synthesis of magnetic $\beta$-cyclodextrin-chitosan/graphene oxide as nanoadsorbent and its application in dye adsorption and removal. Colloids and Surfaces B: Biointerfaces. 2013 Mar; 103:601-7. <DOI>.

64. Salahuddin NehalA, EL-Daly HosnyA, El Sharkawy RehabG, Nasr BeshoyT. Synthesis and efficacy of PPy/CS/GO nanocomposites for adsorption of ponceau 4R dye. Polymer. 2018 Jun; 146:291-303. <DOI $>$.

65. Kamal S, Khan F, Kausar $H$, Khan MS, Ahmad $A$, Ishraque Ahmad $S$, et al. Synthesis, characterization, morphology, and adsorption studies of ternary nanocomposite comprising graphene oxide, chitosan, and polypyrrole. Polymer Composites. 2020 Sep;41(9):3758-67. $\leq \mathrm{DOI}$.

66. Salahuddin NA, El-Daly HA, El Sharkawy RG, Nasr BT. Nano-hybrid based on polypyrrole/chitosan/grapheneoxide magnetite decoration for dual function in water remediation and its application to form fashionable colored product. Advanced Powder Technology. 2020 Apr;31(4):1587-96. <DOI>.

67. Wang Z, Zhang G, Li Y. Preparation of Chitosan/Polyacrylamide/Graphene Oxide Composite Membranes and Study of Their Methylene Blue Adsorption Properties. Materials. 2020 Oct $2 ; 13(19): 4407$. <DOI>.

68. Chang Z, Chen Y, Tang S, Yang J, Chen Y, Chen $S$, et al. Construction of chitosan/polyacrylate/graphene oxide composite physical hydrogel by semi-dissolution/acidification/sol-gel transition method and its simultaneous cationic and anionic dye adsorption properties. Carbohydrate Polymers. 2020 Feb;229:115431. <DOI>.

69. Fu J, Xin Q, Wu X, Chen Z, Yan Y, Liu S, et al. Selective adsorption and separation of organic dyes from aqueous solution on polydopamine 
microspheres. Journal of Colloid and Interface Science. 2016 Jan;461:292-304. <DOI>.

70. Guo X, Yang H, Liu Q, Liu J, Chen R, Zhang $H$, et al. A chitosan-graphene oxide/ZIF foam with anti-biofouling ability for uranium recovery from seawater. Chemical Engineering Journal. 2020 Feb;382:122850. <DOI $>$.

71. Li J, Wang X, Zhao G, Chen C, Chai Z, Alsaedi $A$, et al. Metal-organic framework-based materials: superior adsorbents for the capture of toxic and radioactive metal ions. Chem Soc Rev. 2018;47(7):2322-56. <DOI $>$.

72. Sirajudheen $\mathrm{P}$, Karthikeyan $\mathrm{P}$, Ramkumar $\mathrm{K}$, Meenakshi $S$. Effective removal of organic pollutants by adsorption onto chitosan supported graphene oxide-hydroxyapatite composite: A novel reusable adsorbent. Journal of Molecular Liquids. 2020 Nov;318:114200. <DOI>.

73. Azizkhani S, Mahmoudi E, Abdullah N, Ismail MHS, Mohammad AW, Hussain SA. Synthesis and Characterisation of Graphene Oxide-Silica-Chitosan for Eliminating the $\mathrm{Pb}$ (II) from Aqueous Solution. Polymers. 2020 Aug 26;12(9):1922. <DOI>.

74. Chen J, Ma Y, Wang L, Han W, Chai Y, Wang T, et al. Preparation of chitosan/SiO2-loaded graphene composite beads for efficient removal of bilirubin. Carbon. 2019 Mar;143:352-61. <DOI>.

75. Yan M, Huang W, Li Z. Chitosan cross-linked graphene oxide/lignosulfonate composite aerogel for enhanced adsorption of methylene blue in water. International Journal of Biological Macromolecules. 2019 Sep;136:927-35. <DOI>.

76. Zeng W, Liu Y, Hu X, Liu S, Zeng G, Zheng B, et al. Decontamination of methylene blue from aqueous solution by magnetic chitosan lignosulfonate grafted with graphene oxide: effects of environmental conditions and surfactant. RSC Adv. 2016;6(23):19298-307. <DOI>.

77. Ge H, Ma Z. Microwave preparation of triethylenetetramine modified graphene oxide/chitosan composite for adsorption of
Cr(VI). Carbohydrate
Oct; $131: 280-7 .<$ DOI $>$.

Polymers.

2015

78. Kovtun A, Campodoni E, Favaretto L, Zambianchi M, Salatino A, Amalfitano $S$, et al. Multifunctional graphene oxide/biopolymer composite aerogels for microcontaminants removal from drinking water. Chemosphere. 2020 Nov;259:127501. <DOI>.

79. Wu Z, Deng W, Zhou W, Luo J. Novel magnetic polysaccharide/graphene oxide @Fe304 gel beads for adsorbing heavy metal ions. Carbohydrate Polymers. 2019 Jul;216:119-28. <DOI>.

80. Wei H, Han L, Tang Y, Ren J, Zhao Z, Jia L. Highly flexible heparin-modified chitosan/graphene oxide hybrid hydrogel as a super bilirubin adsorbent with excellent hemocompatibility. J Mater Chem B. 2015;3(8):1646-54. <DOI>.

81. Huang $T$, Shao $Y$, Zhang Q, Deng $Y$, Liang Z, Guo $F$, et al. Chitosan-Cross-Linked Graphene Oxide/Carboxymethyl Cellulose Aerogel Globules with High Structure Stability in Liquid and Extremely High Adsorption Ability. ACS Sustainable Chem Eng. 2019 May 6;7(9):8775-88. <DOI>. 
